\title{
BMJ Open Statin associated adverse reactions in Latin America: a scoping review
}

\author{
Manuel Urina-Jassir (1) , ${ }^{1}$ Tatiana Pacheco-Paez, ${ }^{2}$ Carol Paez-Canro, ${ }^{3}$ \\ Miguel Urina-Triana (i) ${ }^{1,4}$
}

To cite: Urina-Jassir M, Pacheco-Paez T, Paez-Canro C, et al. Statin associated adverse reactions in Latin America: a scoping review. BMJ Open 2021;11:e050675. doi:10.1136/ bmjopen-2021-050675

- Prepublication history and additional supplemental material for this paper are available online. To view these files, please visit the journal online (http://dx.doi.org/10.1136/ bmjopen-2021-050675).

Received 25 February 2021 Accepted 09 September 2021

Check for updates

(C) Author(s) (or their employer(s)) 2021. Re-use permitted under CC BY-NC. No commercial re-use. See rights and permissions. Published by BMJ.

${ }^{1}$ Clinical Research Department Fundación del Caribe para la Investigación Biomédica, Barranquilla, Atlantico, Colombia ${ }^{2}$ Evidence-Based Therapeutics Group, Clinical Pharmacology, Universidad de La Sabana, Chia, Colombia

${ }^{3}$ Sexually Transmitted Infections Group, Cochrane Collaboration, Universidad Nacional de Colombia, Bogota, Colombia ${ }^{4}$ Facultad de Ciencias de la Salud, Universidad Simón Bolívar, Barranquilla, Atlántico, Colombia

\section{Correspondence to} Dr Miguel Urina-Triana; murina1@unisimonbolivar. edu.co

\section{ABSTRACT}

Objectives We aim to describe the frequency and type of adverse drug reactions (ADRs) in patients on statins in published studies from Latin American (LATAM) countries. Design Scoping review.

Methods A literature search was conducted in three databases (PubMed, EMBASE and LILACS) in addition to a manual search in relevant journals from LATAM universities or medical societies. A snowballing technique was used to identify further references. Randomised controlled trials (RCTs) and observational studies between 2000 and 2020 were included. Studies were considered eligible if they included adults on statin therapy from LATAM and reported data on ADRs. Data on ADRs were abstracted and presented by study design.

Results Out of 8076 articles, a total of 20 studies were included (7 RCTs and 13 observational studies). We identified three head-to-head statin RCTs, two statinversus-policosanol RCTs and only two placebo-controlled trials. The statin-related ADRs frequency ranged from $0 \%$ to $35.1 \%$ in RCTs and $0 \%$ to $28.4 \%$ in observational studies. The most common ADRs were muscle-related events including myalgia and elevated creatine phosphokinase. Other reported ADRs were gastrointestinal symptoms, headache and altered fasting plasma glucose. Conclusions We identified differences in the frequency of ADRs in both observational studies and RCTs from LATAM countries. This could be due to the absence of standard definitions and reporting of ADRs as well as differences among the study's interventions, population characteristics or design. The variability of ADRs and the absence of definitions are similar to studies from other geographical locations. Further placebo-controlled trials and real-world data registries with universal definitions should follow.

\section{INTRODUCTION}

Statin therapy is recommended as an initial treatment for dyslipidaemia and cardiovascular disease (CVD) prevention. ${ }^{1-3}$ However, the role of statins in the primary prevention of CVD has been quite controversial, especially in subjects with low baseline risks. ${ }^{45}$ Recently, a meta-analysis of 94283 patients without a history of CVD found that statins reduced the risk of events such as non-fatal myocardial infarction (absolute risk differences (RD) -20 to -25 to -15 per 10000 person-years), cardiovascular mortality (RD: -11 to -16 to -5 per 10000 person-years)
Strengths and limitations of this study

To our knowledge, this is the first review describing the statin-related adverse reactions in published studies from Latin America.

- A thorough literature search in multiple databases and a manual search was conducted.

- A lack of statin versus placebo randomised controlled trials in the region was identified.

- Most of the randomised controlled trials had small sample sizes and short follow-up periods.

- Some multinational studies including Latin American populations were excluded due to the impossibility of obtaining the segregated data by region.

and major cardiovascular events (RD -14 to -20 to -19 per 10000 person-years). Concurrently, the aforementioned meta-analysis indicated the need for benefit-harm balance assessments to determine whether statins provide a net benefit. ${ }^{6}$ On the other hand, Koskinas et al conducted a meta-analysis of 152507 patients with a known history of atherosclerotic CVD, among whom statin therapy significantly reduced major vascular events (cardiovascular death, myocardial infarction, coronary revascularisation and stroke) compared with those who were not administered statin therapy (RR: $0.77,95 \%$ CI 0.71 to 0.83$){ }^{7}$

Notably, despite its benefits, adherence to statin treatment is lower than expected even among patients with a previous cardiovascular event or at high cardiovascular risk. ${ }^{8} \mathrm{~A}$ systematic review of 19 studies evaluating the predictors of statin adherence in the primary prevention setting found that $17.8 \%-79.2 \%$ of the patients were considered adherent to the therapy. ${ }^{9}$ Furthermore, Kim et al conducted an observational study in Korea that included 3807 patients with a recent history of acute myocardial infarction and reported that discontinuing statin therapy was associated with increased mortality. ${ }^{10}$ Multiple reasons for statin non-adherence have been cited, including treatment-related 
factors such as a high dose or developing adverse drug reactions (ADRs). ${ }^{11}$

ADRs related to statins, also known as 'statin-associated symptoms (SAS)', include statin-associated muscle symptoms (SAMS; myalgia, elevated creatine kinase levels and rhabdomyolysis), diabetes mellitus (DM) and elevated liver enzymes. ${ }^{12}$ The prevalence of these events varies depending on the study design. The Patient and Provider Assessment of Lipid Management (PALM) registry in the USA evaluated primary care patients and found that $41.8 \%$ of the 5316 current statin users reported at least one SAS. ${ }^{13}$ Meanwhile, in a systematic review of randomised controlled trials (RCTs), the percentage of patients with muscle complaints was $12.7 \%$ compared with $12.4 \%$ from the placebo group. ${ }^{14}$

Ischaemic heart disease is the most common cause of death in Latin America (LATAM).$^{15}$ Despite a decrease in mortality in some countries in LATAM, the overall trends in this region are unfavourable when compared with those of North America. ${ }^{16}$ A cross-sectional study evaluated the prevalence of dyslipidaemia in seven big cities of LATAM, finding a high prevalence ranging from $38.7 \%$ to $68.1 \% .{ }^{17}$ However, the percentage of patients on lipidlowering therapy was low $(8 \%-45 \%) .{ }^{17}$ There is a noticeable dearth of studies evaluating the use of statins or the prevalence of ADRs in LATAM. Therefore, in this scoping review, our objectives were to evaluate the frequency of the ADRs related to statin use and describe the different types of ADRs encountered in studies from LATAM.

\section{METHODS}

\section{General considerations}

A scoping review was conducted following the Arksey and O'Malley framework ${ }^{18}$ that was later enhanced by Levac et al. ${ }^{19}$ We followed the Preferred Reporting Items for Systematic Reviews and Meta-Analyses extension for Scoping Reviews (PRISMA) in conducting the review. ${ }^{20}$ We opted to use a scoping review approach to provide a general overview of the available data on statin-related ADRs, including RCTs and observational studies. Furthermore, we did not anticipate finding many placebo-controlled RCTs for a meta-analysis. Regarding terminology, we used the term ADRs, defined as 'an appreciably harmful or unpleasant reaction, resulting from an intervention related to the use of a medicinal product ${ }^{21}$ throughout the review.

\section{Objectives and research question}

Our objectives were (1) to describe the frequency/prevalence of ADRs and (2) to characterise the different types of ADRs experienced by patients undergoing statin therapy in studies from LATAM countries. We defined our research question using the Population, Intervention, Comparison and Outcome strategy. ${ }^{22}$ This resulted in the following, P: Adults from LATAM; I: Statin therapy (monotherapy or in combination); C: Any (None, Placebo, Other Statin, Other lipid-modifying therapy
(LMT)) and O: ADRs related to statin therapy, statin intolerance, statin withdrawal.

\section{Eligibility criteria}

We included observational (cross-sectional, cohort and case-control studies) and experimental studies (RCTs) that studied adult patients (older than 18 years) undergoing treatment with statins (monotherapy or in combination) from LATAM countries. The studies had to incorporate data on ADRs. The articles included were published between 2000 and 2020. We excluded review articles, case reports or series, and citations in a language that was not Spanish, English or Portuguese given the population of interest (LATAM countries). Notably, during the screening, we did not have to exclude any article based on its language.

\section{Information sources and search strategy}

We conducted systematic literature searches through PubMed, EMBASE and LILACS for articles published from inception to August 2020. We used keywords related to statins, ADRs and common statin-related ADRs (muscular, gastrointestinal). The last search was performed on 4 September 2020. The search strategy applied in two of the databases (PubMed and EMBASE) can be accessed in online supplemental material. Additionally, we manually searched university journals from LATAM as well as cardiology, endocrinology and lipid society journals of LATAM countries to find unindexed articles, conference abstracts, or grey literature related to the topic. Lastly, a snowballing technique was employed to identify potential references for the review.

\section{Study selection}

Two independent reviewers (MU-J and TP-P) screened the articles by title and abstract using the web application Rayyan. ${ }^{23}$ The resulting references were accessed in full text and two authors (MU-J and TP-P) separately selected the articles based on the eligibility criteria. Disagreements were resolved by a third author (CP-C).

\section{Data items and data charting}

We developed two independent extraction forms for observational studies and RCTs. Both forms included the general data of the publication (author, year of publication, country, study design, publication type, main objective, funding/conflicts of interest) and the characteristics of the participants (total population, LATAM country/ countries, mean age, gender, race, comorbidities, other drugs). Additionally, data regarding statins (whether the participants were on a statin or not, type of statin, dose if available) and outcomes (general outcomes, ADRs, 'statin intolerance' with definition if available) were collected. The data extraction form for the RCTs varied by including data about the intervention and comparison of each trial. Whenever we encountered multinational studies without division by region or country, we contacted the corresponding author via email to solicit the needed information. If the reply was negative or no 
answer was received, the study was excluded. Moreover, we included multinational trials in which $>80 \%$ of the study population were from LATAM countries to boost our results.

\section{Synthesis of results}

We considered that a narrative synthesis was the best approach for presenting our results given the heterogeneity of the studies. The synthesis was presented according to the study design: RCTs and observational studies. Data on the studies' characteristics, population characteristics, statins, and ADRs are reported.

\section{Patient and public involvement}

No patient or public was involved in the design, conduction, reporting, or dissemination of this research.
RESULTS

\section{Study selection}

A total of 8076 articles resulted from the initial search. After duplicates were removed, 7862 records were screened by title and abstract, resulting in 180 articles accessed in full text. Finally, 20 articles fulfilled the prespecified inclusion criteria. A PRISMA ${ }^{24}$ flow chart summarising our selection is shown in figure 1 . From the included articles, 7 were RCTs and 13 were observational studies ( 8 cross-sectional and 5 cohort $(2$ retrospective and 3 prospective)) studies).

\section{Randomised controlled trials}

The studies were from four different LATAM countries (Brazil, Cuba, Mexico and Venezuela) ${ }^{25-29}$ in addition to two multinational studies. ${ }^{3031}$ From the latter, one included
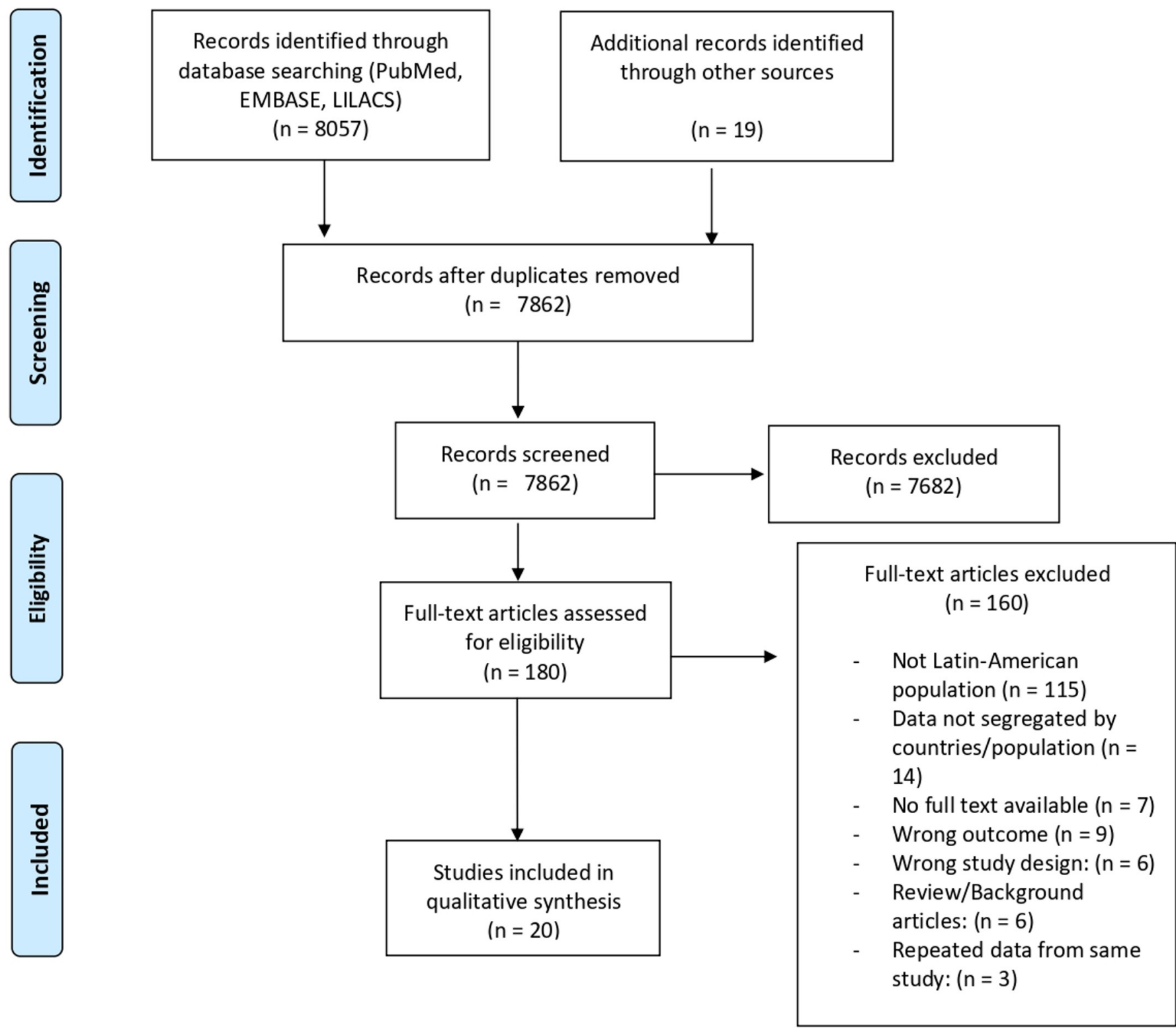

Figure 1 PRISMA ${ }^{24}$ flow chart for selection of studies. PRISMA, Preferred Reporting Items for Systematic Reviews and MetaAnalyses. 
participants from Brazil, Colombia, Mexico and Venezuela ( $87 \%$ of the study population).$^{30}$ The other divided the outcomes by self-reported ethnicity and the Hispanic group included $88.8 \%$ of patients from South and Central America (Argentina, Brazil, Chile, Colombia, Costa Rica, El Salvador, Mexico, Panama, Uruguay and Venezuela). ${ }^{31}$ Four of the RCTs were industry funded, ${ }^{2528} 3031$ while the funding source was not disclosed in three. ${ }^{26} 2729$

A total of 4209 patients were included across the RCTs. The mean age of the participants ranged from 50 to 66 years. ${ }^{25-30}$ One author reported a median age of 67 years. ${ }^{31}$ The proportion of male participants ranged from $16.3 \%$ to $53.2 \%$ while female participation ranged from $46.8 \%$ to $83.7 \%$, except for one study that included only women. ${ }^{27}$ The reported baseline characteristics and comorbidities included in the RCTs varied in each report. Mean body mass index (BMI) ranged from 25.7 to $29.1 \mathrm{~kg} / \mathrm{m}^{2} .{ }^{2627}{ }^{29-31}$ The most common comorbidities reported were hypertension (HTN) $(30.6 \%-78 \%),{ }^{25-31}$ DM $(9.4 \%-54 \%),{ }^{25-30}$ obesity $(28.6 \%-41.9 \%)^{25-2730}$ and smoking $(10.4 \%-30.5 \%) .{ }^{25-27} 3031$

Regarding the intervention and comparison, three RCTs were direct statin comparisons ${ }^{25} 2930$ with one of them being statin/ezetimibe comparison, ${ }^{25}$ two were statin versus policosanol, ${ }^{26} 27$ and two were placebocontrolled. ${ }^{28} 31$ These studies evaluated both the efficacy and safety of the interventions. The primary outcome or endpoint was mainly the efficacy of treatment; this was evaluated mostly by changes in the low-density lipoprotein cholesterol (LDL-C), ${ }^{25-30}$ the achievement of pre-established LDL-C goals, ${ }^{25} 2930$ or the reduction of cardiovascular events. ${ }^{31}$ For ADRs evaluation, both clinical and laboratory ADRs were frequently included. Most articles did not include a clear definition of ADRs. Table 1 summarises the characteristics of the RCTs.

\section{Statin ADRs among head-to-head statin (or combination) RCTs}

In Brazil, Vattimo et al conducted a trial comparing rosuvastatin/ezetimibe versus simvastatin/ezetimibe with a previous simvastatin run-in. ${ }^{25}$ The frequency of ADRs in the rosuvastatin/ezetimibe arm was $12 \%$ during the run-in phase and $19.5 \%$ while on the intervention. On the other hand, the simvastatin/ezetimibe arm presented ADRs in $15.8 \%$ of the participants during the run-in phase and in $23.8 \%$ during the treatment phase. ${ }^{25}$ The most common ADRs were increased fasting plasma glucose and myalgia. ${ }^{25}$ Rodríguez-Roa et al compared two different presentations of atorvastatin (amorphous highly soluble and crystalline) in Venezuela. ${ }^{29}$ They segregated the ADRs by type of atorvastatin and reported a frequency of $12.5 \%$ and $35.1 \%$ among the amorphous highly soluble and crystalline atorvastatin participants, respectively. ${ }^{29}$ This resulted in an overall prevalence of $24.6 \%$. The most common ADRs were creatine phosphokinase (CPK) elevation $(11.5 \%)$, abdominal colic $(2.9 \%)$ and dizziness $(2.9 \%)$ while $2.9 \%$ discontinued treatment. ${ }^{29}$ Furthermore, Fonseca et al (DISCOVERY PENTA study) compared rosuvastatin to atorvastatin in a multinational study. ${ }^{30}$ They reported treatment-related ADRs in $25.7 \%$ and $21.2 \%$, respectively; serious ADRs in $1.2 \%$ and $2.0 \%$, respectively; and discontinuation of treatment in $4.8 \%$ and $1.8 \%$, respectively. ${ }^{30}$ The most common ADRs were headache $(1.8 \%$ and $1.6 \%$, respectively), myalgia $(1.2 \%$ and $1.4 \%$, respectively) and dizziness $(1.2 \%$ and $0.4 \%$, respectively). ${ }^{30}$

\section{Statin ADRs among statin versus other LMT RCTs}

Both trials from Cuba compared $10 \mathrm{mg}$ policosanol to a statin. Castaño et al compared policosanol to lovastatin and found ADRs in $6.9 \%$ and $30 \%$ of the subjects, respectively. ${ }^{26}$ From the lovastatin arm, $6.7 \%$ discontinued treatment; the most common ADRs were gastrointestinal manifestations. ${ }^{26}$ Meanwhile, Fernández et al compared policosanol and fluvastatin, ${ }^{27}$ and reported that $8.6 \%$ and $20 \%$ of the patients in the policosanol and fluvastatin groups, respectively, experienced ADRs. ${ }^{27}$ From the fluvastatin arm, three patients discontinued the study due to ADRs; the most common ADRs were nausea (5.7\%) and abdominal discomfort $(5.7 \%){ }^{27}$

\section{Statin ADRs among placebo-controlled RCTs}

Talavera et al compared the efficacy of rosuvastatin to placebo in reducing triglyceride levels in Mexican patients and reported 'no serious adverse events related to treatment. ${ }^{28}$ The Hispanic population of the JUPITER study comparing rosuvastatin versus placebo presented serious ADRs in $8.2 \%$ of the participants in the rosuvastatin group compared with $7.9 \%$ in the placebo group. ${ }^{31}$ The event rate for serious ADRs per 100 person-years during the follow-up period was 4.75 and 4.55 for rosuvastatin and placebo, respectively. ${ }^{31}$ The number of participants in each group was obtained from the main article of the JUPITER trial. ${ }^{32}$

\section{Overall statin ADRs among RCTs}

Table 2 presents the prevalence of ADRs in each trial divided by each comparison. Overall, the prevalence of ADRs in the seven included RCTs ranged from $0 \%$ to $35.1 \%$.

\section{Observational studies}

The studies included were from Argentina (n=3), ${ }^{33-35}$ Brazil $(n=4),{ }^{36-39}$ Colombia $(n=4),{ }^{40-43}$ and Mexico $(n=2) \cdot{ }^{44} 45$ A total population of 4680 subjects were evaluated across the studies. The mean age of the participants ranged from 52.5 to 66.4 years. ${ }^{33} 37-414344$ Two authors reported median ages of $45^{35}$ and 56 years. ${ }^{42}$ One of the studies evaluated the polypharmacy exclusively in elderly patients (mean age: 72 ) ${ }^{45}$ Female gender ranged from $11.3 \%$ to $77.8 \%$. When reported, BMI ranged from 26.8 to $29.2 \mathrm{~kg} / \mathrm{m}^{2}$. ${ }^{38-41} 44$ The reported baseline conditions, comorbidities, and lifestyle characteristics varied among the studies. The most common conditions described were HTN $(41.2 \%-88.8 \%),{ }^{33}{ }^{36-44} \mathrm{DM}$ $(9.9 \%-63 \%), 3336-414344$ coronary heart disease $(10.1 \%-$ $40.6 \%), 33744344$ smoking $(2.8 \%-65.8 \%)^{33} 36-39414344$ 


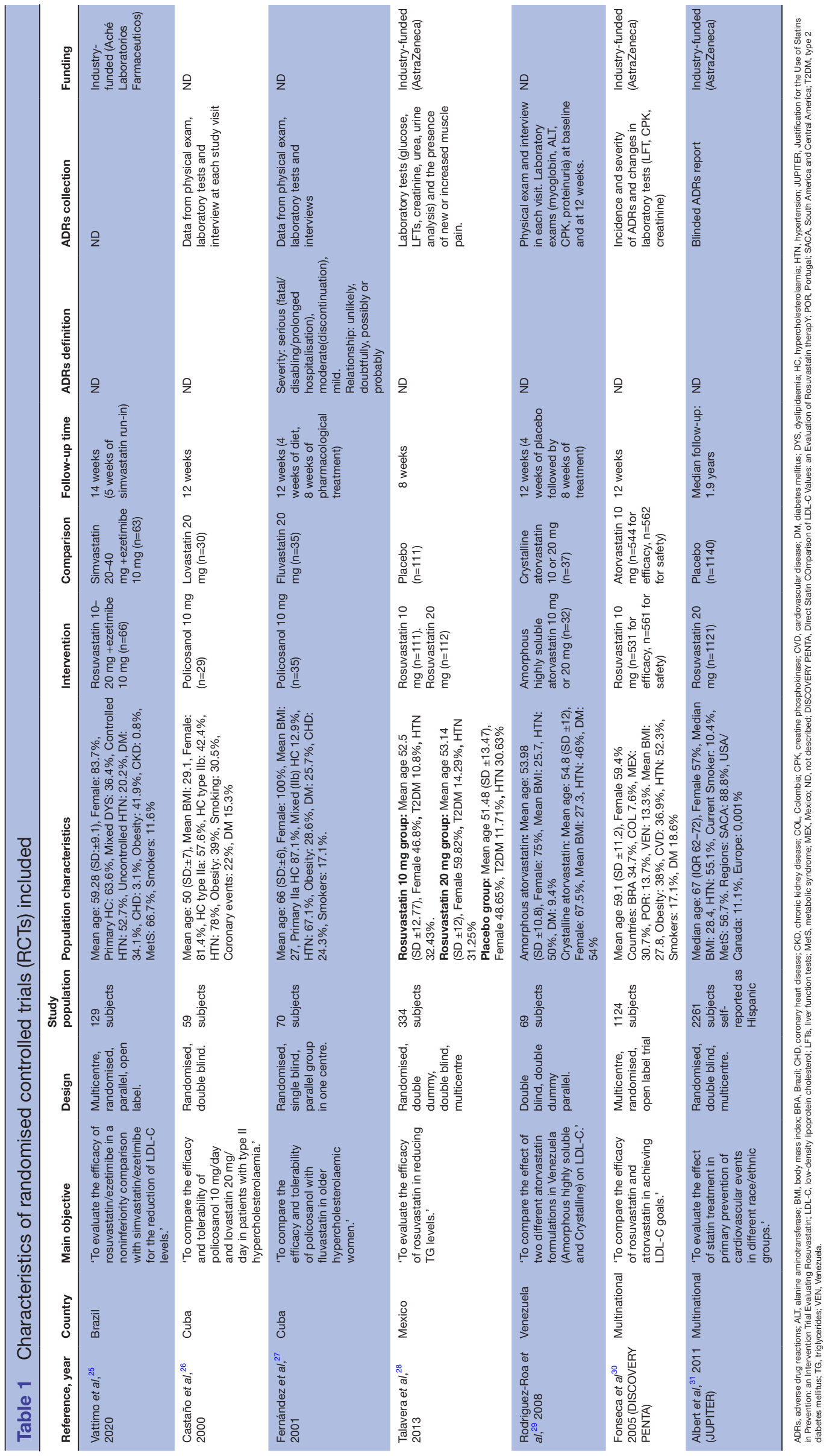


Table 2 Prevalence and type of statin related ADRs classified by RCT comparison

\begin{tabular}{|c|c|c|c|c|c|c|}
\hline \multirow[b]{2}{*}{ Reference } & \multirow[b]{2}{*}{$\begin{array}{l}\text { Statin or } \\
\text { comparison }\end{array}$} & \multirow[b]{2}{*}{$\begin{array}{l}\text { ADRs \% } \\
\text { (n/total pop.) }\end{array}$} & \multicolumn{4}{|l|}{ Type of ADRs } \\
\hline & & & Muscle related* & GI symptoms $†$ & $\begin{array}{l}\text { FPG } \\
\text { alterations }\end{array}$ & Headache \\
\hline \multicolumn{7}{|c|}{ Head-to-head statin (or combination) RCTs } \\
\hline \multirow[t]{2}{*}{$\begin{array}{l}\text { Rodriguez-Roa et } \\
a{ }^{29}{ }^{29} 2008\end{array}$} & $\begin{array}{l}\text { Amorphous highly } \\
\text { soluble atorvastatin } \\
10-20 \mathrm{mg}\end{array}$ & $12.5(4 / 32)$ & $6.3 \%$ mild increased CPK & $\begin{array}{l}6.3 \% \text { ( } 3.1 \% \text { : } \\
\text { abdominal colic, } \\
\text { 3.1\%: mild ALT } \\
\text { elevation) }\end{array}$ & $\mathrm{N} / \mathrm{A}$ & N/A \\
\hline & $\begin{array}{l}\text { Crystalline } \\
\text { atorvastatin 10-20 } \\
\text { mg }\end{array}$ & $35.1(13 / 37)$ & $\begin{array}{l}16.2 \% \text { increased CPK and } \\
2.7 \% \text { increased myoglobin }\end{array}$ & $\begin{array}{l}5.4 \% \text { divided } \\
\text { (2.7\% diarrhoea } \\
\text { and abdominal } \\
\text { colic, } 2.7 \% \text { mild } \\
\text { ALT elevation) }\end{array}$ & $\mathrm{N} / \mathrm{A}$ & N/A \\
\hline \multirow{2}{*}{$\begin{array}{l}\text { Fonseca et al } \\
\text { (DISCOVERY } \\
\text { PENTA) }{ }^{30} 2005\end{array}$} & Rosuvastatin $10 \mathrm{mg}$ & $25.7(144 / 561)$ & $\begin{array}{l}2.4 \% \text { ( } 1.2 \% \text { myalgia, } 1.2 \% \\
\text { back pain) }\end{array}$ & $\begin{array}{l}0.6 \% \text { ALT }>3 \text { times } \\
\text { ULN }(3 / 532)\end{array}$ & $\mathrm{N} / \mathrm{A}$ & $1.8 \%$ \\
\hline & Atorvastatin $10 \mathrm{mg}$ & $21.2(119 / 562)$ & $\begin{array}{l}1.8 \% \text { ( } 1.4 \% \text { myalgia, } 0.4 \% \\
\text { back pain), } 0.2 \% \text { ( } 1 / 542) \\
\text { CPK > } 10 \text { times ULN) }\end{array}$ & $\begin{array}{l}0.2 \% \text { ALT }>3 \text { times } \\
\text { ULN }(1 / 541)\end{array}$ & $\mathrm{N} / \mathrm{A}$ & $1.6 \%$ \\
\hline
\end{tabular}

\begin{tabular}{|c|c|c|c|c|c|c|}
\hline \multicolumn{7}{|c|}{ Statin versus other LMT RCTs } \\
\hline \multirow{2}{*}{$\begin{array}{l}\text { Castaño et al, }{ }^{26} \\
2000\end{array}$} & Policosanol $10 \mathrm{mg}$ & $6.9(2 / 29)$ & $N / A$ & $3.4 \%$ & $\mathrm{~N} / \mathrm{A}$ & N/A \\
\hline & Lovastatin 20 mg & $30(9 / 30)$ & $3.3 \%$ muscle cramps & $20 \%$ & $\mathrm{~N} / \mathrm{A}$ & N/A \\
\hline & Fluvastatin 20 mg & $20(7 / 35)$ & N/A & $\begin{array}{l}11.4 \%(5.7 \% \\
\text { nausea, } 5.7 \% \\
\text { abdominal } \\
\text { discomfort) }\end{array}$ & N/A & N/A \\
\hline
\end{tabular}

Placebo-controlled RCTs

\begin{tabular}{|c|c|c|c|c|c|c|}
\hline \multirow[t]{2}{*}{$\begin{array}{l}\text { Talavera et al, } \\
2013\end{array}$} & $\begin{array}{l}\text { Rosuvastatin } 10 \text { or } \\
20 \mathrm{mg}\end{array}$ & 'No serious ADRs' & $\mathrm{N} / \mathrm{A}$ & $\mathrm{N} / \mathrm{A}$ & $\mathrm{N} / \mathrm{A}$ & N/A \\
\hline & Placebo & 'No serious ADRs' & $\mathrm{N} / \mathrm{A}$ & $\mathrm{N} / \mathrm{A}$ & N/A & N/A \\
\hline \multirow[t]{2}{*}{$\begin{array}{l}\text { Albert et al, } \\
\text { (JUPITER) }^{31} 2011\end{array}$} & Rosuvastatin 20 mg & $\begin{array}{l}8.2 \\
(92 / 1121) \\
\text { event rate§: } 4.75\end{array}$ & $\begin{array}{l}\text { Myopathy: } 0.17 \% \text {, event } \\
\text { rate§: } 0.1\end{array}$ & $\begin{array}{l}\text { ALT >3 times ULN: } \\
0.17 \% \text {, event } \\
\text { rate§: } 0.1\end{array}$ & $\begin{array}{l}\text { Newly } \\
\text { diagnosed } \\
\text { DM: } 2.1 \% \text {, } \\
\text { Event rate§: } \\
1.19\end{array}$ & $\mathrm{~N} / \mathrm{A}$ \\
\hline & Placebo & $\begin{array}{l}7.9(91 / 1140) \\
\text { event rate§: } 4.55\end{array}$ & Myopathy: 0\% & $\begin{array}{l}\text { ALT >3 times ULN: } \\
0.08 \% \text {, event } \\
\text { rate§: } 0.05\end{array}$ & $\begin{array}{l}\text { Newly } \\
\text { diagnosed } \\
\text { DM: } 2.1 \% \text {, } \\
\text { event rate§: } \\
1.16\end{array}$ & $\mathrm{~N} / \mathrm{A}$ \\
\hline
\end{tabular}

*Includes myalgia, increased CPK, myopathy, rhabdomyolysis.

tIncludes diarrhoea, nausea, gastritis, full stomach, vomiting, liver function tests alteration.

$\ddagger$ This study included a previous simvastatin run-in for 5 weeks where ADRs were reported in $12 \%$ and $15.8 \%$ of patients in the rosuvastatin/ ezetimibe and simvastatin/ezetimibe, respectively.

$\S$ Reported as 'adverse event rates per 100 person-years during follow-up'.

ADRs, adverse drug reactions; ALT, alanine aminotransferase; CPK, creatine phosphokinase; DM, diabetes mellitus; FPG, fasting plasma glucose;

GI, gastrointestinal; JUPITER, Justification for the Use of Statins in Prevention: an Intervention Trial Evaluating Rosuvastatin; LMT, lipid modifying therapy; N/A, not available; DISCOVERY PENTA, DIrect Statin COmparison of LDL-C Values: an Evaluation of Rosuvastatin therapY; RCTs, randomised controlled trials; Ros/Eze, rosuvastatin/ezetimibe; Sim/Eze, simvastatin/ezetimibe; ULN, upper limit of normal.

and hypothyroidism $(2.4 \%-25.4 \%) .{ }^{373841-43}$ In addition, a study evaluated the efficacy and safety of rosuvastatin in HIV-positive patients. ${ }^{35}$ The funding sources of the studies were as follows: industry $(n=4), 33414244$ nonindustry $(\mathrm{n}=4),{ }^{36-39}$ none $(\mathrm{n}=1)^{45}$ and not described $(\mathrm{n}=4) .{ }^{34} 354043$ 
The type of statin evaluated varied among the observational studies. Two reports described statins as a group. ${ }^{3344}$ One study included elderly patients taking pravastatin. ${ }^{45}$ Two additional studies assessed participants on individual statins (atorvastatin ${ }^{39}$ and rosuvastatin ${ }^{35}$ ). The remaining manuscripts evaluated multiple types of statins, such as atorvastatin, lovastatin, simvastatin, rosuvastatin, pravastatin and fluvastatin, as well as combinations with ezetimibe or fibrate. Table 3 summarises the characteristics and definitions for ADRs (when available) of the observational studies.

\section{Statin ADRs among cross-sectional studies}

Eight studies had a cross-sectional design. ${ }^{33} 3436384143-45$ Cuneo $e t$ al studied the Argentine population from a large multinational study. ${ }^{33}$ They stated that intolerance to a higher dose of statin was the reason for not prescribing the highest dose available for statin in $16.7 \%$ of the cases. The most commonly described symptoms were muscle-related and gastrointestinal. ${ }^{33}$ Spalvieri et al found an overall ADRs prevalence of 23\% in an Argentine population. ${ }^{34}$ These were specified as liver function tests (LFTs) abnormalities (none >three times the upper limit of normal (ULN)) or muscle-related symptoms/ CPK elevation. ${ }^{34}$ Only one participant suffered a severe ADR (CPK elevation $>10$ times ULN) ${ }^{34}$ Furthermore, do Nascimento et al evaluated the state of statin use in Brazil and found that simvastatin was the preferred statin $(90.3 \%)$; notably, $6.5 \%$ of the users manifested poor adherence (defined as 'missing at least one dose of a statin in the past 7 days'). ${ }^{36}$ Four participants $(10.6 \%$ of poorly adherent patients and $0.6 \%$ of the total population) reported ADRs as the reason for their nonadherence. ${ }^{36}$ Ferreira Castro et al evaluated patients on simvastatin or atorvastatin and found that $17 \%$ presented muscle-related ADRs and $2.5 \%$ presented a threefold increase in LFTs. ${ }^{38}$

Ruiz et al assessed the state of dyslipidaemia in Colombia and mentioned atorvastatin, rosuvastatin, lovastatin, and simvastatin as the most used statins. ${ }^{41}$ ADRs frequency ranged from $4.0 \%$ to $5.2 \%$, and statin intolerance was reported in $2.6 \% .^{41}$ The most common complaints were myalgia, elevated CPK, elevated alanine aminotransferase and gastritis. ${ }^{41}$ Furthermore, Toro Escobar et al evaluated CPK alterations in patients on statins in a centre in Colombia and showed that $11.1 \%$ presented elevated CPK levels, but only $0.6 \%$ developed a threefold increase. ${ }^{43}$ Additionally, 28.4\% of the patients complained of muscle pain, $26 \%$ of fatigue, and $15.9 \%$ of weakness. ${ }^{43}$ BelloChavolla et al studied the Mexican population included in a large multinational study and found that 'lack of tolerability' was the reason for not prescribing the highest dose of statins in $13 \%$, describing muscle pain as the most common complaint. ${ }^{44}$ Carrillo-Alarcon et al reported that from 24 elderly patients on pravastatin, $12.5 \%$ developed ADRs (nausea and dyspepsia). ${ }^{45}$

\section{Statin ADRs among cohort studies}

Five studies had a cohort design. ${ }^{35} 37394042$ Bottaro et al assessed rosuvastatin in an HIV-positive population on antiretroviral therapy and found that $3.8 \%$ developed ADRs. ${ }^{35}$ They developed myalgia or gastrointestinal complaints, while one participant had a prominent CPK elevation (19 $000 \mathrm{UI} / \mathrm{L}) .{ }^{35}$ Smiderle et al studied patients on simvastatin or atorvastatin and found an ADRs frequency of $14.9 \%$; myalgia or abnormalities in CPK and/or LFTs were described. ${ }^{37}$ Meanwhile, Santos et al assessed LDL receptor mutations in familial hypercholesterolaemia subjects on atorvastatin and found that $11.6 \%$ and $0 \%$ of the participants developed myalgia and rhabdomyolysis, respectively, during a 1-year follow-up. ${ }^{39}$ Zuluaga-Quintero et alfound an ADRs prevalence of $1.6 \%$ among patients with dyslipidaemia on atorvastatin or lovastatin; gastrointestinal distress was the most common symptom. ${ }^{40}$ Interestingly, Diaztagle et al reported no ADRs among patients on rosuvastatin or statin in combination with fibrates or ezetimibe in patients from 12 Colombian cities; however they noted that only $39 \%$ of the patients attended their second follow-up. ${ }^{42}$

\section{Overall statin ADRs among observational studies}

Table 4 presents the frequency of ADRs related to statin therapy among the observational studies divided by study design. Overall, the frequency of ADRs among the included observational studies ranged from $0 \%$ to $28.4 \%$.

\section{DISCUSSION}

This scoping review identified a high variation in the frequency of statin-related ADRs among experimental and observational studies in LATAM countries. Among the RCTs, the percentage of patients with ADRs ranged from $0 \%$ to $35.1 \%$, whereas in the observational studies, this proportion ranged from $0 \%$ to $28.4 \%$. Most studies did not clearly define the ADRs, while in those that did, the definitions and types of ADRs reported were heterogeneous. The most frequently encountered ADRs were muscle-related manifestations, including CPK elevation, myalgia and myopathy.

The included RCTs differed in crucial aspects such as the type of statin, doses, follow-up time and, most importantly, comparisons. We included three head-tohead, two statin-versus-policosanol, and two placebocontrolled trials. From the latter, Talavera $e t$ al reported no serious ADRs in either group, ${ }^{28}$ while Albert et al described a similar event rate for developing ADRs in both groups. ${ }^{31}$ A meta-analysis described that many of the commonly reported and serious ADRs occurred at a similar rate in both statins and placebo. ${ }^{46}$ Notably, Penson et al introduced the 'drucebo' concept in an attempt to better describe the 'placebo' and 'nocebo' effects due to drugs. ${ }^{47}$ They conducted a systematic review evaluating SAMS in RCTs that included both open-label and blinded phases and described that $38 \%-78 \%$ of the SAMS in RCTs could be due to a 'negative drucebo effect' rather 


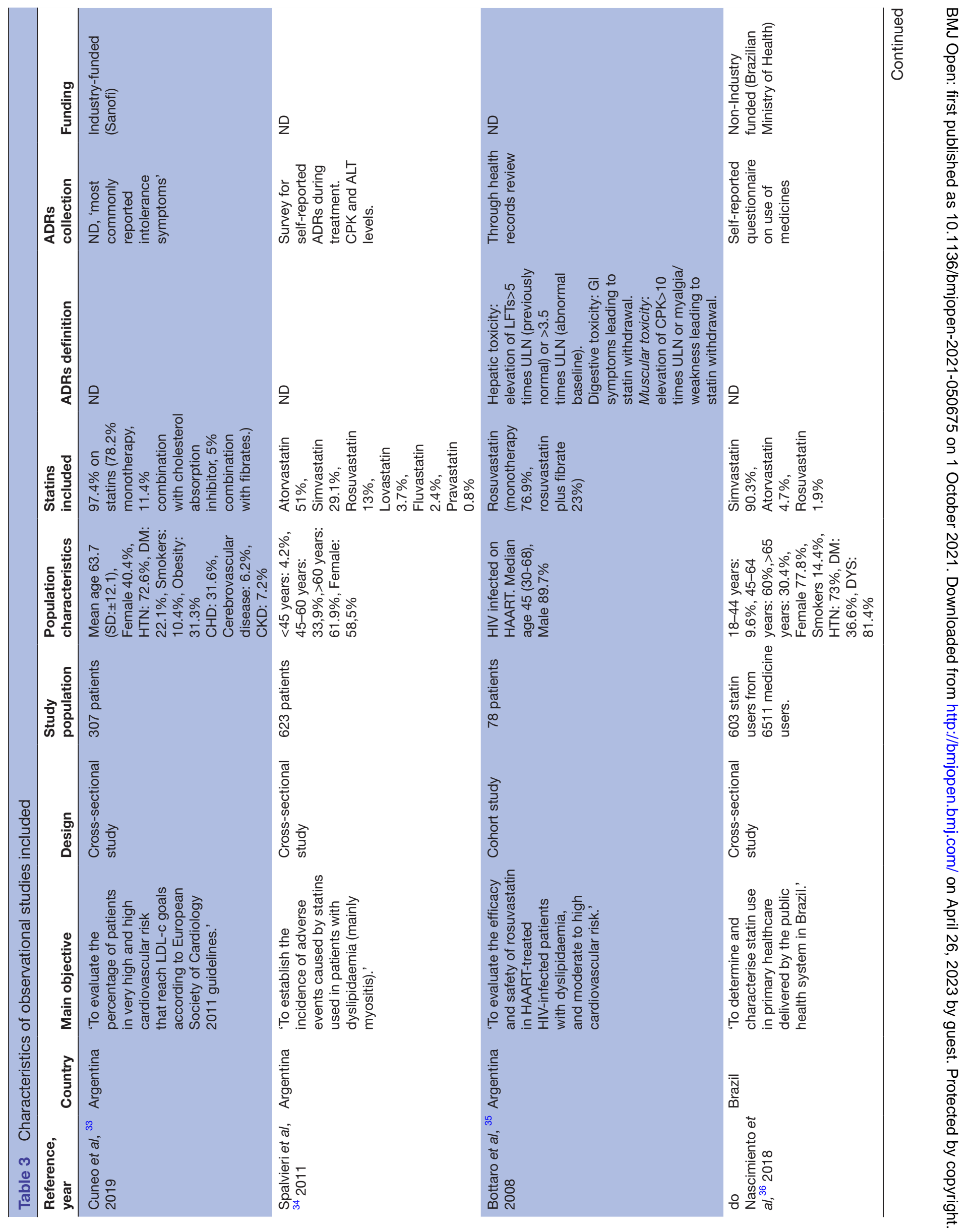




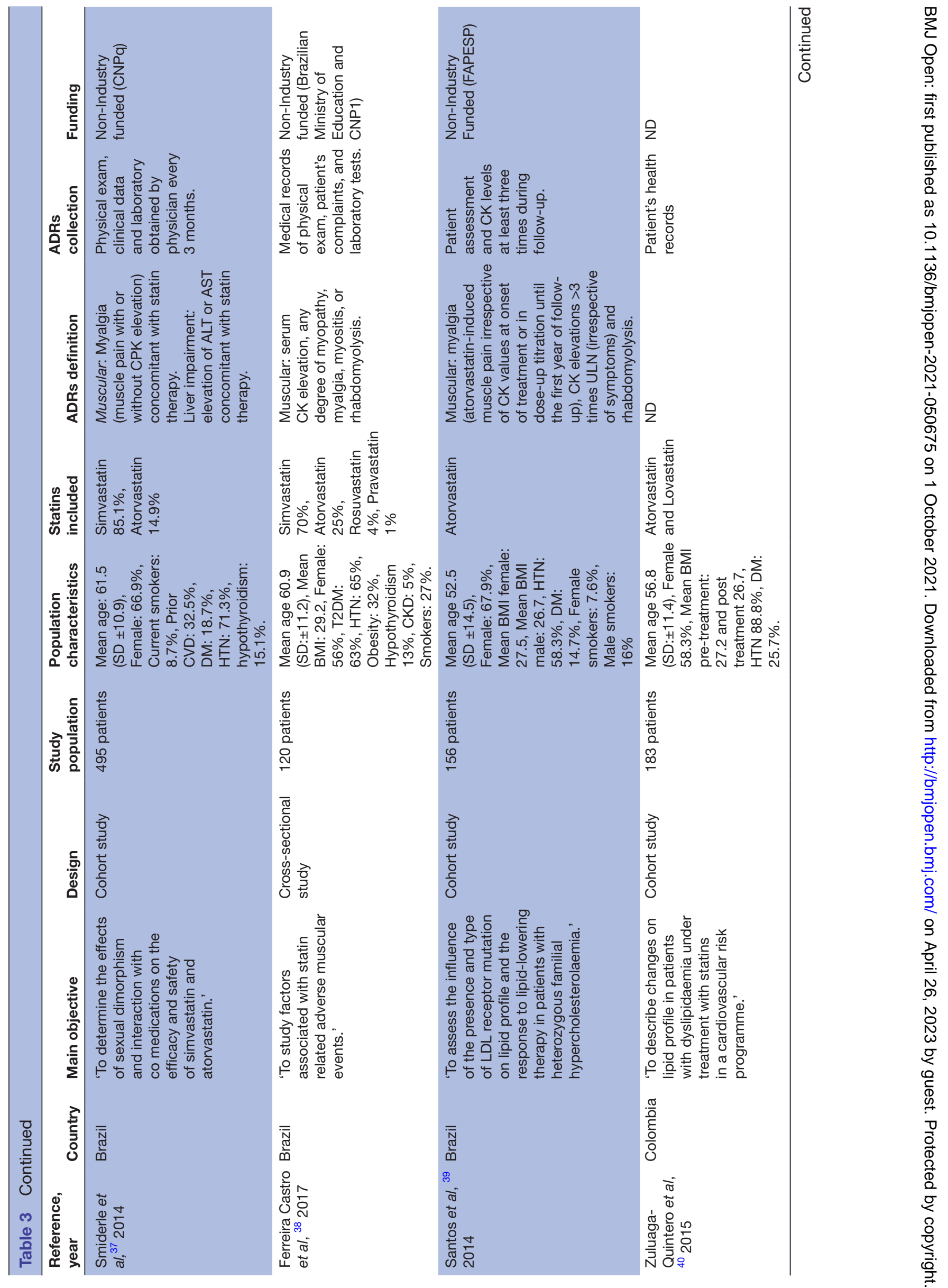




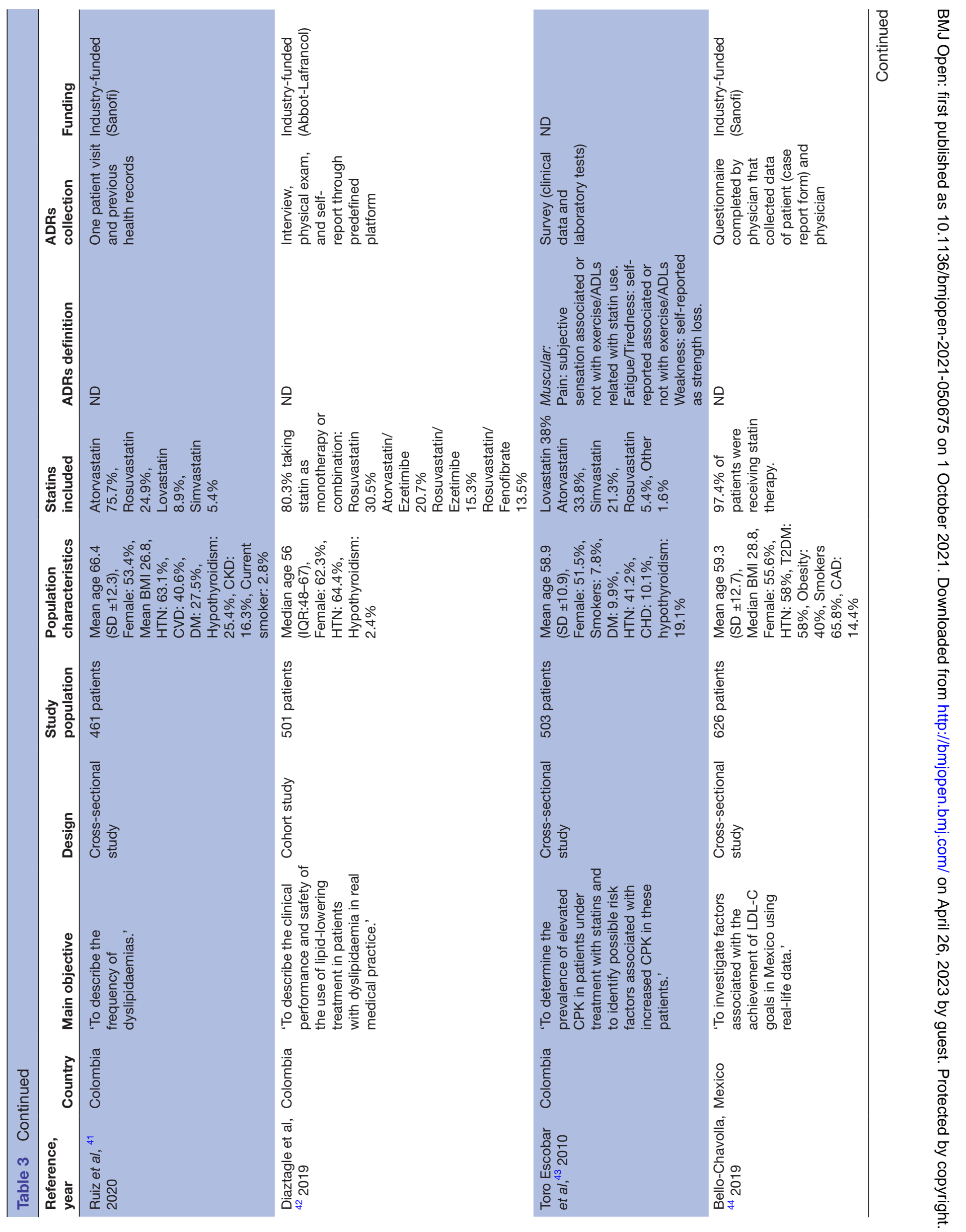




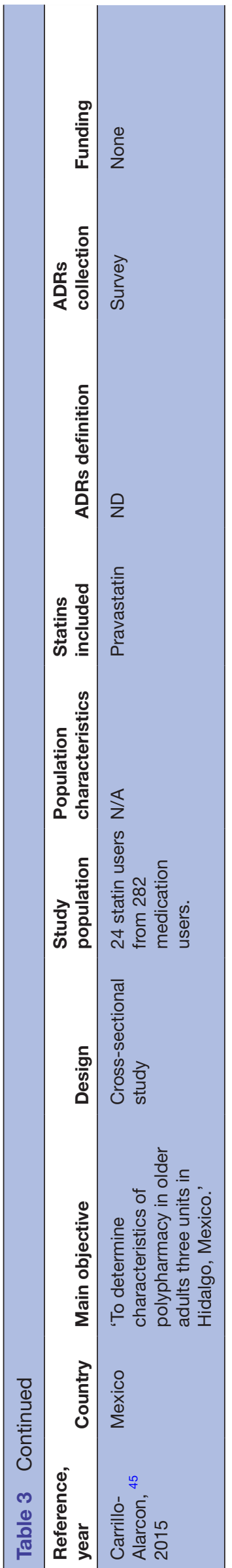

than to a direct effect of statin treatment. ${ }^{47}$ On the other hand, the nocebo effect has been debated. ${ }^{48}$ Factors such as possible average neutrality of effects, patient selection and selective inclusion of certain outcomes may lead to misinterpretation of RCT data on ADRs. ${ }^{48}$

Regarding the observational studies, the lower end of this range was attributed to the findings from Diaztagle et al, who considered that this low rate of ADRs can be explained by the nonattendance of the subjects in their second follow-ups after the prescription of therapy. ${ }^{42}$ In contrast to these findings, a cross-sectional study from the PALM registry in the USA found that $41.8 \%$ of current statin users and $63.2 \%$ of former statin users complained of at least one symptom associated with statin therapy. ${ }^{13}$ Moreover, a multinational clinician web-based survey was conducted in two different studies which described that, according to physicians, the estimated percentage of patients unable to tolerate statins was $6 \%(2 \%-12 \%$ among 13 countries ${ }^{49}$ and $2.7 \%(1.1 \%-4.8 \%$ among 12 countries),${ }^{50}$ with muscular symptoms being the most common overall. ${ }^{49} 50$

The differences in the definitions and reporting of ADRs may account for the variations in the frequency in our review. Most of the included RCTs did not define ADRs. This problem was also encountered by Ganga $e t$ $a l$, who conducted a meta-analysis of muscle-related ADRs and found that $98 \%$ of the studies did not provide a definition for them. ${ }^{14}$ Other factors have been posited to affect the appearance of ADRs in statin users. ${ }^{51}$ Some authors have stated that female gender and advanced age may be risk factors for muscle-related ADRs. ${ }^{51}{ }^{52}$ From the included articles, two exclusively comprised older populations ${ }^{2745}$ while one focused only on female participants. ${ }^{27}$ In addition, comorbidities such as metabolic syndrome, obesity, and HTN or the use of concomitant drugs may also impact the rate of ADRs. ${ }^{51}$ The included studies varied greatly on their baseline characteristics and comorbidities like DM, HTN and obesity. One study included only HIV-positive patients on antiretrovirals. ${ }^{35}$ The included studies evaluated patients on different statins and doses. A dose-related response has been described previously in some ADRs, such as muscle-related ones ${ }^{53}$ and rhabdomyolysis. ${ }^{54}$ An additional factor that may affect the estimation of ADRs in published studies is the selection of patients in RCTs, as subjects with an increased risk of developing muscle-related ADRs may have been excluded. ${ }^{55}$ Lastly, the association of funding sources with outcomes on RCTs has been discussed.$^{56}$ Approximately half $(3 / 7)$ and a third (4/13) of the included RCTs and observational studies, respectively, did not have information available regarding the funding source.

The present review has some limitations that need to be mentioned. First, we had to exclude 14 multinational studies that fulfilled the initial eligibility criteria because the data were not segregated by region, leading to the loss of valuable information for our review. Second, most of the RCTs had small sample sizes and short follow-up periods. Studies with small samples can affect the 
Table 4 Prevalence and type of statin related ADRs classified by study design

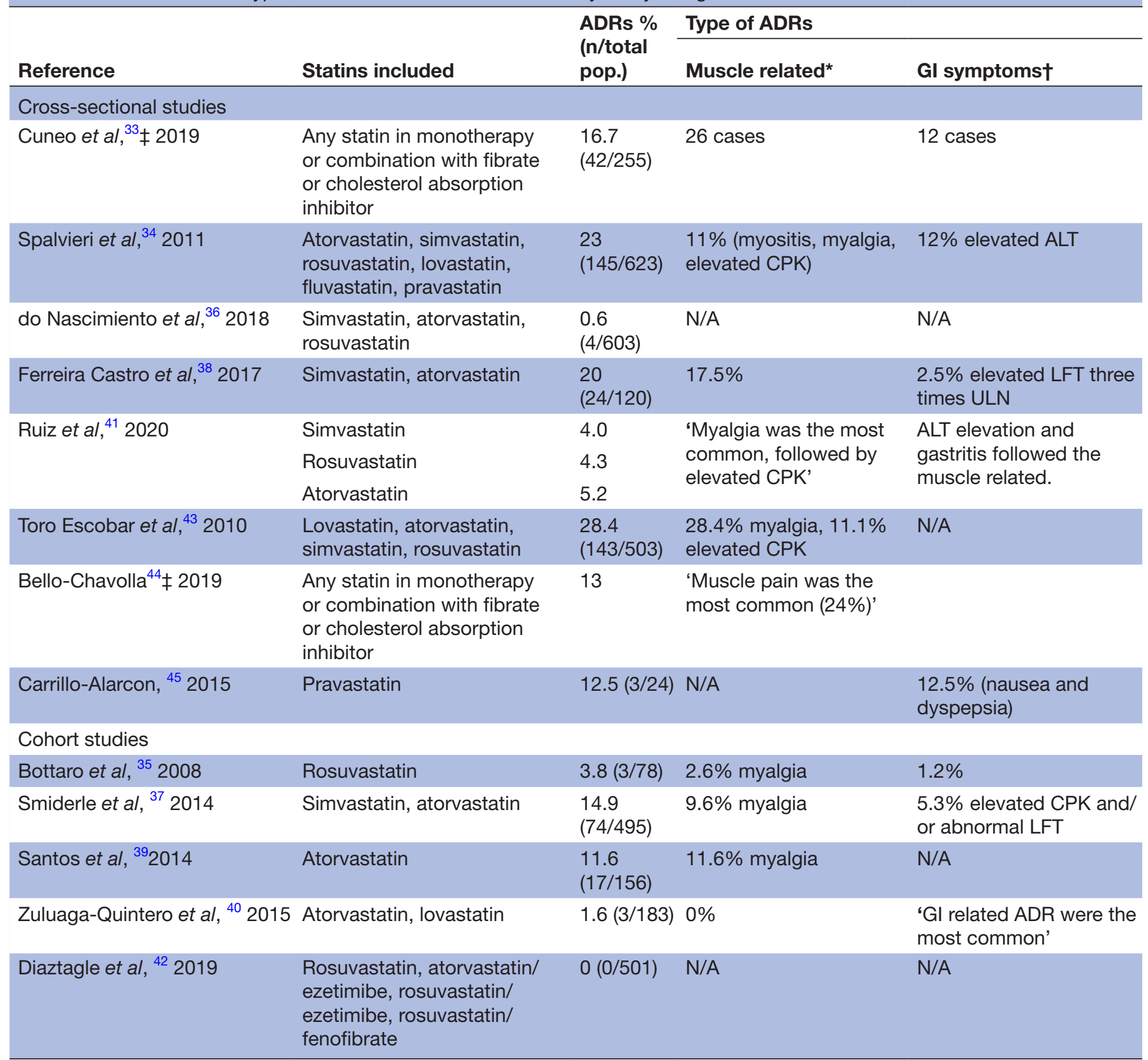

*Includes myalgia, increased CPK, myopathy, rhabdomyolysis.

†Includes diarrhoea, nausea, gastritis, full stomach, vomiting, liver function tests alteration.

$\ddagger$ These authors describe the reasons for not prescribing the highest dose possible of statins and the percentage that is due to intolerance.

ADRs, adverse drug reactions; ALT, alanine aminotransferase; CPK, creatine phosphokinase; FPG, fasting plasma glucose; Gl,

gastrointestinal; LFT, liver function test; N/A, not available; ULN, upper limit of normal.

precision of outcomes in RCTs. ${ }^{57}$ In this case, it can lead to overestimation or underestimation of the prevalence of ADRs, especially when percentages are used. RCTs with short follow-up periods may miss data on long-term ADRs. ${ }^{58}$ Third, three out of seven RCTs were head-tohead comparisons of statins resulting in a more of an observational type of result as no alternative or placebo was present for comparison. Fourth, an inherent limitation of any review is relying on the ADRs reported in manuscripts, and not necessarily all of those reported by patients which could lead to underreporting of ADRs. ${ }^{59}$

To our knowledge, this is the first review to collate and describe the data of statin-related ADRs in the LATAM population. We conducted a thorough systematic search in multiple databases and an important manual search, including studies from various countries from the region and two large multinational studies. This scoping review identified an important gap in the literature regarding 
statin ADRs in LATAM. Our work should encourage researchers and/or public health entities in LATAM countries, especially those where no studies were identified, to develop studies or registries that describe the use of statins, including indications for treatment, the most prescribed/used statin, ADR frequency and discontinuation rates. In addition, the use of clear and consistent ADRs definitions in upcoming studies is crucial.

\section{CONCLUSIONS}

In this review, we identified differences in the frequency of ADRs among published studies in LATAM. A high variation in ADRs reporting was found to be a reflection of the differences in the definitions and measurements of ADRs among statin studies in the region. The variability of ADRs and the absence of definitions are similar to those noted in studies from other geographic locations. These deficits indicate the need for the standardisation of definitions and measurements for statin ADRs in future studies. Further placebo-controlled trials with extensive eligibility criteria and longer follow-ups, as well as realworld data studies, evaluating statin ADRs in LATAM are warranted.

\section{Twitter Miguel Urina-Triana @MAUrinaTriana}

Contributors MU-T had the research idea. MU-J, TP-P and MU-T contributed to the conceptualisation of the review. TP-P and CP-C conducted the literature search. MU-J, TP-P and CP-C did the screening of abstracts and full texts. MU-J, TP-P, CP-C and MU-T contributed to the data charting. MU-J, TP-P, CP-C and MU-T interpreted the data. MU-T supervised the review. MU-J wrote the initial manuscript draft. MU-J, TP-P, CP-C and MU-T were involved in the critical revision of the article. All authors read and approved the final draft.

Funding The authors have not declared a specific grant for this research from any funding agency in the public, commercial or not-for-profit sectors.

Competing interests TP-P is currently employed at Novartis, but the company did not fund nor interfere in the conduction or publication of this study; she conducted the work in an independent capacity. CP-C performed this work before her employment at Amgen.

Patient consent for publication Not applicable.

Provenance and peer review Not commissioned; externally peer reviewed.

Data availability statement Data sharing not applicable as no datasets generated and/or analysed for this study. Not applicable. This scoping review was based on already published manuscripts.

Supplemental material This content has been supplied by the author(s). It has not been vetted by BMJ Publishing Group Limited (BMJ) and may not have been peer-reviewed. Any opinions or recommendations discussed are solely those of the author(s) and are not endorsed by BMJ. BMJ disclaims all liability and responsibility arising from any reliance placed on the content. Where the content includes any translated material, BMJ does not warrant the accuracy and reliability of the translations (including but not limited to local regulations, clinical guidelines, terminology, drug names and drug dosages), and is not responsible for any error and/or omissions arising from translation and adaptation or otherwise.

Open access This is an open access article distributed in accordance with the Creative Commons Attribution Non Commercial (CC BY-NC 4.0) license, which permits others to distribute, remix, adapt, build upon this work non-commercially, and license their derivative works on different terms, provided the original work is properly cited, appropriate credit is given, any changes made indicated, and the use is non-commercial. See: http://creativecommons.org/licenses/by-nc/4.0/.

\section{ORCID iDs}

Manuel Urina-Jassir http://orcid.org/0000-0002-1119-3181

Miguel Urina-Triana http://orcid.org/0000-0001-6003-4622
REFERENCES

1 Arnett DK, Blumenthal RS, Albert MA, et al. 2019 ACC/AHA guideline on the primary prevention of cardiovascular disease: Executive summary: a report of the American College of Cardiology/ American heart association Task force on clinical practice guidelines. Circulation

2 Grundy SM, Stone NJ, Bailey AL, et al. 2018 AHAVACC/AACVPR/ AAPA/ABC/ACPM/ADA/AGS/APhA/ASPC/NLA/PCNA Guideline on the Management of Blood Cholesterol: A Report of the American College of Cardiology/American Heart Association Task Force on Clinical Practice Guidelines. J Am Coll Cardiol 2019;73:e285-350.

3 Mach F, Baigent C, Catapano AL, et al. 2019 ESC/EAS guidelines for the management of dyslipidaemias: lipid modification to reduce cardiovascular risk. Eur Heart J 2020;41:111-88.

4 Byrne P, Cullinan J, Smith SM. Statins for primary prevention of cardiovascular disease. BMJ 2019;8:I5674-5.

5 Redberg RF, Katz MH. Statins for primary prevention: the debate is intense, but the data are weak. JAMA 2016;316:1979-81.

6 Yebyo HG, Aschmann HE, Kaufmann M, et al. Comparative effectiveness and safety of statins as a class and of specific statins for primary prevention of cardiovascular disease: a systematic review, meta-analysis, and network meta-analysis of randomized trials with 94,283 participants. Am Heart J 2019;210:18-28.

7 Koskinas KC, Siontis GCM, Piccolo R, et al. Effect of statins and non-statin LDL-lowering medications on cardiovascular outcomes in secondary prevention: a meta-analysis of randomized trials. Eur Heart J 2018;39:1172-80.

8 Guglielmi V, Bellia A, Pecchioli S, et al. Effectiveness of adherence to lipid lowering therapy on LDL-cholesterol in patients with very high cardiovascular risk: a real-world evidence study in primary care. Atherosclerosis 2017;263:36-41.

9 Hope HF, Binkley GM, Fenton S, et al. Systematic review of the predictors of statin adherence for the primary prevention of cardiovascular disease. PLoS One 2019;14:1-38.

$10 \mathrm{Kim} \mathrm{MC,} \mathrm{Cho} \mathrm{JY,} \mathrm{Jeong} \mathrm{HC,} \mathrm{et} \mathrm{al.} \mathrm{Impact} \mathrm{of} \mathrm{postdischarge} \mathrm{statin}$ withdrawal on long-term outcomes in patients with acute myocardial infarction. Am J Cardiol 2015;115:1-7.

11 Ingersgaard MV, Helms Andersen T, Norgaard O, et al. Reasons for Nonadherence to Statins - A Systematic Review of Reviews. Patient Prefer Adherence 2020;14:675-91.

12 Thompson PD, Panza G, Zaleski A, et al. Statin-associated side effects. J Am Coll Cardiol 2016;67:2395-410.

13 Navar AM, Peterson ED, Li S, et al. Prevalence and management of symptoms associated with statin therapy in community practice: insights from the palm (patient and provider assessment of lipid management) registry. Circ Cardiovasc Qual Outcomes 2018;11:1-5.

14 Ganga HV, Slim HB, Thompson PD. A systematic review of statin-induced muscle problems in clinical trials. Am Heart $J$ 2014;168:6-15.

15 Rivera-Andrade A, Luna MA. Trends and heterogeneity of cardiovascular disease and risk factors across Latin American and Caribbean countries. Prog Cardiovasc Dis 2014;57:276-85.

16 Pagan E, Chatenoud L, Rodriguez T, et al. Comparison of trends in mortality from coronary heart and cerebrovascular diseases in North and South America: 1980 to 2013. Am J Cardiol 2017;119:862-71.

17 Vinueza R, Boissonnet CP, Acevedo M, et al. Dyslipidemia in seven Latin American cities: CARMELA study. Prev Med 2010;50:106-11.

18 Arksey H, O'Malley L. Scoping studies: towards a methodological framework. Int J Soc Res Methodol 2005;8:19-32.

19 Levac D, Colquhoun H, O'Brien KK. Scoping studies: advancing the methodology. Implementation Sci 2010;5:1-9.

20 Tricco AC, Lillie E, Zarin W, et al. PRISMA extension for scoping reviews (PRISMA-ScR): checklist and explanation. Ann Intern Med 2018;169:467-73.

21 Aronson JK, Ferner RE. Clarification of terminology in drug safety. Drug Saf 2005;28:851-70.

22 Miller SA, Forrest JL. Enhancing your practice through evidencebased decision making: PICO, learning how to ask good questions. Journal of Evidence Based Dental Practice 2001;1:136-41.

23 Ouzzani M, Hammady H, Fedorowicz Z, et al. Rayyan-a web and mobile APP for systematic reviews. Syst Rev 2016;5:1-11.

24 Moher D, Liberati A, Tetzlaff J, et al. Preferred reporting items for systematic reviews and meta-analyses: the PRISMA statement. PLoS Med 2009;6:e1000097.

25 Vattimo ACA, Fonseca FAH, Morais DC, et al. Efficacy and tolerability of a fixed-dose combination of rosuvastatin and ezetimibe compared with a fixed-dose combination of simvastatin and ezetimibe in Brazilian patients with primary hypercholesterolemia or mixed dyslipidemia: a multicenter, randomized trial. Curr Ther Res Clin Exp 2020;93:100595. 
26 Castaño G, Más R, Fernández JC, et al. Efficacy and tolerability of policosanol compared with lovastatin in patients with type II hypercholesterolemia and concomitant coronary risk factors. Curr Ther Res Clin Exp 2000;61:137-46.

27 Fernández JC, Más R, Castaño G, et al. Comparison of the efficacy, safety and tolerability of Policosanol versus fluvastatin in elderly hypercholesterolaemic women. Clin Drug Investig 2001;21:103-13.

28 Talavera J-O, Martinez G, Cervantes J-L, et al. A double-blind, double-dummy, randomized, placebo-controlled trial to evaluate the effect of statin therapy on triglyceride levels in Mexican hypertriglyceridemic patients. Curr Med Res Opin 2013;29:379-86.

29 Rodríguez-Roa E, Téllez R, Rodríguez F, et al. Evaluación comparativa de la efectividad clínica de DOS formulaciones de atorvastatina en pacientes Con O Sin enfermedad cardiovascular. Rev Latinoam Hipertens 2008;3:129-35 https://www.redalyc.org/ articulo.oa?id=170217040005

30 Fonseca FAH, Ruiz A, Cardona-Muñoz EG, et al. The DISCOVERY PENTA study: a Dlrect Statin COmparison of LDL-C Value--an Evaluation of Rosuvastatin therapY compared with atorvastatin. Curr Med Res Opin 2005;21:1307-15.

31 Albert MA, Glynn RJ, Fonseca FAH, et al. Race, ethnicity, and the efficacy of rosuvastatin in primary prevention: the Justification for the use of statins in prevention: an intervention trial evaluating rosuvastatin (JUPITER) trial. Am Heart J 2011;162:106-14.

32 Ridker PM, Danielson E, Fonseca FAH, et al. Rosuvastatin to prevent vascular events in men and women with elevated C-reactive protein. N Engl J Med 2008;359:2195-207.

33 Cuneo C, Kotliar C, Medrano JC, et al. Logro de Los objetivos de colesterol de lipoproteínas de Baja densidad en 18 países fuera de Europa occidental: estudio Internacional de prácticas de manejo del colesterol (ICLPS) sub análisis argentino. Rev Fed Arg Cardiol 2019;48:86-91 https://www.fac.org.ar/archivo/2/revista/19v48n2/ especial/01/cuneo.php

34 Spalvieri MP, Oyola ME. Estatinas: incidencia de efectos adversos / statins: incidence of adverse effects / Estatinas: incidência de efeitos adversos. Acta Bioquím Clín Latinoam 2011;45:727-65 https://www. redalyc.org/articulo.oa?id=53521525005

35 Gabriel Bottaro E, Caravello Óscar, Gustavo Scapellato P, et al. Rosuvastatina para tratamiento de la dislipidemia en pacientes infectados Con VIH en tratamiento antirretroviral de gran actividad. Experiencia preliminar. Enferm Infecc Microbiol Clin 2008;26:325-9.

36 do Nascimento RCRM, Guerra AA, Alvares J, et al. Statin use in Brazil: findings and implications. Curr Med Res Opin 2018;34:1809-17.

37 Smiderle L, Lima LO, Hutz MH, et al. Evaluation of sexual dimorphism in the efficacy and safety of simvastatin/atorvastatin therapy in a southern Brazilian cohort. Arq Bras Cardiol 2014;103:33-40.

38 Ferreira Castro P, Ribeiro E, Lima Dorea E, et al. Factors associated with statin-related adverse muscular events in adult dyslipidemic outpatients. Bras J Pharm Sci 2017;53:e00199.

39 Santos PCJL, Morgan AC, Jannes CE, et al. Presence and type of low density lipoprotein receptor (LDLR) mutation influences the lipid profile and response to lipid-lowering therapy in Brazilian patients with heterozygous familial hypercholesterolemia. Atherosclerosis 2014;233:206-10.

40 Zuluaga-Quintero N, Arcila-Hincapie L, Bedoya-Lopez DF, et al. Comportamiento del perfil lípidico en paciente Con dislipidemia tratados Con estatinas en Una iPS. CES Salud Pública 2015;6:63-9.
41 Ruiz Álvaro J., Vargas-Uricoechea H, Urina-Triana M, et al. Las dislipidemias Y SU tratamiento en centros de alta complejidad en Colombia. Clin e Investig en Arterioscler 2020;32:101-10.

42 Diaztagle JJ, Castro CA, Buitrago DC. Experiencia en la utilización de hipolipemiantes en una cohorte de pacientes en 12 ciudades colombianas. Rev Medicas UIS 2019;32:13-20.

43 Toro Escobar JM, Toro CMA, Maya GC. Prevalencia de alteraciones de la creatina-fosfoquinasa (CPK) sérica en pacientes que toman estatinas. Med Lab 2010;16:141-52.

44 Bello-Chavolla OY, Aguilar-Salinas CA. Factors influencing achievement of low-density lipoprotein cholesterol goals in Mexico: the International cholesterol management practice study. Rev Invest Clin 2019;71:408-16.

45 Carrillo-Alarcon LC, Chavez-Gallegos D, Ocampo-Torres M, et al. Characterization of polypharmacy in the elderly in three units of health services in Pachuca, Hidalgo. Int Res J Pharm 2015;6:25-30. doi:10.7897/2230-8407.0616

46 Finegold JA, Manisty $\mathrm{CH}$, Goldacre B, et al. What proportion of symptomatic side effects in patients taking statins are genuinely caused by the drug? systematic review of randomized placebocontrolled trials to aid individual patient choice. Eur J Prev Cardiol 2014;21:464-74.

47 Penson PE, Mancini GBJ, Toth PP, et al. Introducing the 'Drucebo' effect in statin therapy: a systematic review of studies comparing reported rates of statin-associated muscle symptoms, under blinded and open-label conditions. J Cachexia Sarcopenia Muscle 2018;9:1023-33.

48 Golomb BA. Misinterpretation of trial evidence on statin adverse effects may harm patients. Eur J Prev Cardiol 2015;22:492-3.

49 Hovingh GK, Gandra SR, McKendrick J, et al. Identification and management of patients with statin-associated symptoms in clinical practice: a clinician survey. Atherosclerosis 2016;245:111-7.

50 Rosenson RS, Gandra SR, McKendrick J, et al. Identification and management of Statin-Associated symptoms in clinical practice: extension of a clinician survey to 12 further countries. Cardiovasc Drugs Ther 2017;31:187-95.

51 Golomb BA, Evans MA. Statin adverse effects : a review of the literature and evidence for a mitochondrial mechanism. Am J Cardiovasc Drugs 2008;8:373-418

52 Bhardwaj S, Selvarajah S, Schneider EB. Muscular effects of statins in the elderly female: a review. Clin Interv Aging 2013;8:47-59.

53 Cham S, Evans MA, Denenberg JO, et al. Statin-associated muscle-related adverse effects: a case series of 354 patients. Pharmacotherapy 2010;30:541-53.

54 Holbrook A, Wright M, Sung M, et al. Statin-associated rhabdomyolysis: is there a dose-response relationship? Can $\mathrm{J}$ Cardiol 2011;27:146-51.

55 Rosenson RS. Trial designs for statin muscle intolerance. Curr Opin Lipidol 2017;28:488-94.

56 Falk Delgado A, Falk Delgado A. The association of funding source on effect size in randomized controlled trials: 2013-2015 - a crosssectional survey and meta-analysis. Trials 2017;18:125.

57 Lewis SC, Warlow CP. How to spot bias and other potential problems in randomised controlled trials. J Neurol Neurosurg Psychiatry 2004;75:181-7

58 Hemkens LG. How routinely collected data for randomized trials provide long-term randomized real-world evidence. JAMA Netw Open 2018;1:e186014.

59 Heneghan C, Goldacre B, Mahtani KR. Why clinical trial outcomes fail to translate into benefits for patients. Trials 2017;18:122. 